\title{
Analysis of on Intelligent Community Based on Multi-Living Agent
}

\author{
Bin Li' ${ }^{1}$ Chao Liu \\ ${ }^{1}$ College of Automation, Northwestern Polytechnical University, Xi'an, China \\ ${ }^{2}$ The Ministry of Industry and Information Technology Software and Integrated Circuit Promotion Center, Beijing, China \\ Email: zjlhm@189.cn
}

How to cite this paper: Li, B. and Liu, C. (2017) Analysis of on Intelligent Community Based on Multi-Living Agent. Journal of Computer and Communications, 5, 49-56.

https://doi.org/10.4236/jcc.2017.512005

Received: September 4, 2017

Accepted: October 27, 2017

Published: October 30, 2017

Copyright $\odot 2017$ by authors and Scientific Research Publishing Inc. This work is licensed under the Creative Commons Attribution International License (CC BY 4.0).

http://creativecommons.org/licenses/by/4.0/

\begin{abstract}
A new research method for intelligent community based on multi-living agent was presented. The intelligent community system architecture and the application specific intellectual endowment were analyzed in the paper. The prevalence of islands of information on data integration solution was given. This method can improve the integration of intelligent community and accelerate the development speed of the intelligent community.
\end{abstract}

\section{Keywords}

Multi-Living Agent, Complex Information Systems, Intelligent Community, Wisdom Endowment, Data Integration

\section{Introduction}

With the explosion of knowledge, cloud computing and mobile Internet and other next-generation applications of information technology in the community continue to develop and more intelligent community in community management was brought in the concept of wisdom. Smart community is a new concept of community management and a new model of social management innovation under the new situation. Intelligent community regards the happiness of community residents as a starting point. By creating a smart community service to facilitate community residents, it can speed up the construction of harmonious community and promote regional social progress [1].

The main object of community constitution is residential and family, so application of the intelligent community will permeate into every aspect of residents' life. The goal of intelligent community is to form a complete set of data-sharing system [2], so as to provide residents with complete, comprehensive 
and convenient base services. It is a high degree of autonomy, distributed collaborative complex system, facing a variety of challenges such as huge amounts of data, large user, complex application environments and different audiences. But in the actual construction process, the intelligent community systems formed a plurality of information islands, because different departments are independent with each other and decentralized management. Scattered data caused by this reason, has seriously hindered the development of intelligent community.

In this paper, multi-living agent theory-that aims at dealing with complex information system-is introduced into the field of intelligent community [3]. Intelligent community system architecture and application specific intellectual endowment are analyzed. Widespread information on islands of data integration solution is given, which improves the possibilities of integration of intelligent community system, and provides good research direction to optimize the intelligent community systems in the future [4].

\section{Summary of Intelligent Community}

Traditional city has been replaced by smart city. Because community construction is the foundation of wisdom urban construction, intelligent community is inevitably an important support and indispensable component of the smart city. Wisdom community building aims through the use of intelligent technology and methods to integrate various existing community resources and services, so as to innovate community management. By meeting the needs of community service management and other demands, intelligent community provides a wide range of social management services for different types of community groups, such as modern governments, commercial, entertainment, distance education, home health care, and mutual aid and so on. Intelligent community can also promote community development and improve life quality of residents. In wisdom urban construction, community services management will be regard as a guide about how to develop. Resources will be comprehensive utilization and short-term behavior will be prohibited. Furthermore, community services management should be supported in many aspects. Looking at the above factors, community services management will achieve remarkable results [5].

Currently, Shanghai, Beijing, Shenzhen, Ningbo, Hangzhou, Wuhan, and Wuxi, over 100 cities proposed the target to create wisdom city, related planning and implementation project and activities will be gradually launched. As an important part of wisdom city, wisdom community will make full use of Internet and the Internet of things, which involves smart buildings, smart home, network monitoring, smart hospital, city lifeline management, food and drug management, ticket management, family nursing, personal health, digital life and many other areas. Creating wisdom community should seize the great opportunities in the new round of technological revolution and the information industry innovation wave, make full use of developed information communications (ICT) industry, related technology about RFID, telecommunications business and the 
excellent based facilities information. Building community development of wisdom environment should form new modes [6], for example: life base on mass information and smart filter processing, industry development, social management, etc. It is new form of community building for future [7].

Take a look at about technology, wisdom community refers to through the use of intelligent technology and methods, integrate existing services community resources, provide communities member with a variety of convenient services, such as government, business, entertainment, education, health care and life mutual and so on. From the application of directions, intelligent community should realize the objectives of "use intelligent chief to raise efficiency, use wisdom to improve people's livelihood, use wisdom home to create intelligent life, use wisdom community enhance the quality of community" [8].

\section{Basic Theories of Multi-Living Agent}

Something designed for artificial systems that can be used to analyze complex information architecture, which in recent years became one of the main theories of complex information systems, named (MLA), a complex data system with the multi-living agent. "multi" mapping has complex information systems of nature property, such as multi-profile, multi-levels, multi-subsystem interwoven, and multifunction, "multi" and "agent" collection, further reflect above property features, and "activity" is gives system activity, characterize complex information systems survival development, hire in movement process, contain with "process" are is has limits of, complex information systems although features advanced complete, but as the evolution of "environment", it also has decline and fall (activity recession), "activity" Characterizes of normal play and the existence of systems of systems [9].

Method based on the analysis of active agents in complex information systems can decompose complex information system functionality from the system level into sub-agent in different levels and the agent activity can be expressed function from the system profile. Active agents in a complex information system characterize self-organization mechanism in high level by consultation, self-organization mechanism of abnormal results is on behalf of system exception occurred. The research method of using "Activity" embedded in the characterization of complex multi-agent information system is very important for the role of information system function. In short, active agent theory is an effective study method to complex information systems research, which can provide effective solutions to solve real-world problems, and improve the performance of complex information systems.

\section{Overview of Intelligent Community Based on Multi-Living Agent}

Wisdom community is a complex of information systems, which make full of next-generation emerging technology such as cloud computing and property 
networking, involve many area like wisdom home, wisdom property, wisdom Chief, personal health and digital life, etc. With excellent advantage as developed of information communications industry, advanced of RFID related technology, telecommunications business and the information based facilities, built community development of wisdom environment, formed based on mass information and smart filter processing of new form. Intelligent Community system generally consists of five areas: infrastructure, cloud, database group platform, application and service system and support system, in a service-oriented light top design, is committed to providing comprehensive and efficient public services to residents of security and orderly living in urban environment and harmony facilities.

For intelligent community system, we can using the theory of multi-living agent to analyze, which is equivalent to using the theory of multi-living agent to analyze a complex information system. From a point of systems, smart community is a complex information system which contains decision support capabilities and associated with further smart city decision-making problems. In this complex information system, the "active" means that the protection of residents' services at the top level effectiveness while "active" also represent a proxy function properly and try to prolong its functioning cycle. "Multi-active" represents a system of coordination between the various agents and try best to prolong the functionality of the system formation. At the same time, various agents may be further subdivided into smaller, layer-by-layer decomposition community until the concrete realization of active agent units. Based on the above analysis, Figure 1 shows the structure of intelligent community system based on the multi-living active agents.

The intelligent community based on the multi-living agent is made up by the summary of huge amount of data, which provides a powerful data services, such as: deep integration, analysis, mining, and the development, so the most convenient service for residents can be provided. The system mainly includes five layers and three security agents. The basis agent of the first layer mainly provides the fundamental environment for data acquisition, including all hardware environments. The second layer database agent mainly includes four big database sub-agents, such as: business database agent, log database agent, database exchange agents and the sensing information database agent. The third layer cloud computing agent mainly implements various heterogeneous network data exchange and computing. The fourth layer management service agent mainly provides direct service for the community residents by multiple sub-agents, such as wisdom furniture agent, wisdom pension agent and remote service agent. The fifth layer service agent mainly displays form of residents get access to services. At the same time, the security system (includes security agent, standard specification agent and system security agent) ensures the security and integrity of each agent through three ways of technology security, safety operation and safety management. Thus, the intelligent community system based on multi-living agent is a complex information system of multi-level and multi-profile. 


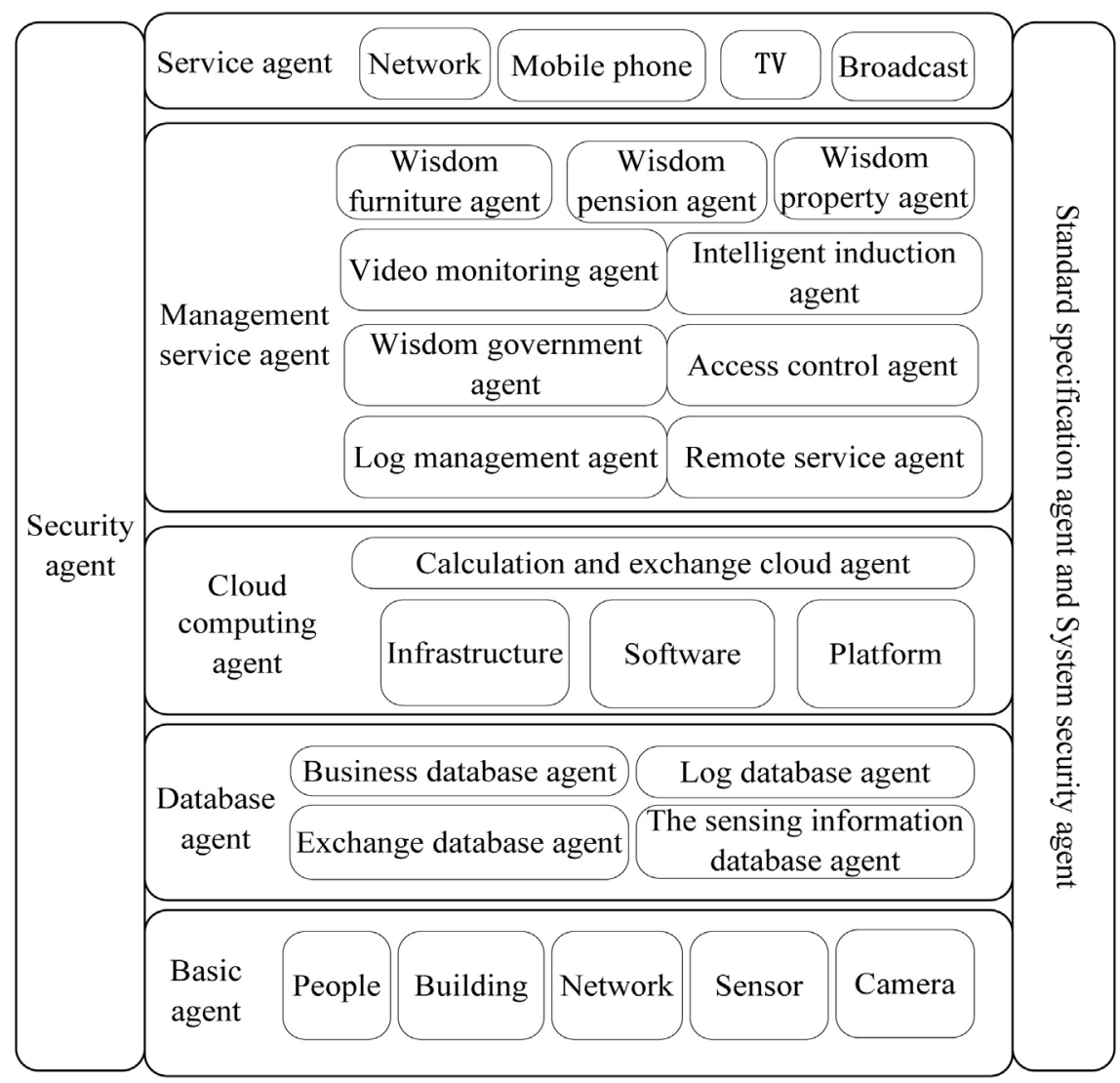

Figure 1. The structure of intelligent community system based on the multi-living agent.

In a word, the complex information system of the intelligent community based on multi-living agent negotiates together with the overall function through the five agents, and controlled by security agent, standard specification agent and system security agent. By connecting all the agents together, solving the island problem of information and integrating the information resources, we can complete data sharing system and improve the overall performance of the intelligent community system.

\section{Applied Analysis of the Intelligent Community Based on the Multi-Living Agent}

The application of intelligent community works with the residents' daily life, which has a strong demand for special people's life safeguard service. Under the busy and fast-paced circumstance of today we don't have enough time to take care of the family. As the reason of body and age, disabled people, especially lonely elderly, urgently need advanced technical means to help them solve the practical problems encountered in the daily life.

In order to meet the modernized life for the old man to live in, wisdom pension agent as a fourth layer management service sub-agent of intelligent community, mainly includes four functional sub-agents: activity for aged management agent, service for aged management agent, home-based care for the 
aged agent and institutional pension agency. The agent is built with family, community and professional services, which can provide the socialized services to solve the problem in daily life for home-based elders. The frame is shown in Figure 2.

Now as an actual application for example, we analyze the application of wisdom pension in intelligent community with the theory of complex information system using multi-living agent. The frame is shown in Figure 3.

We can see from the above analysis, the system is divided into 5 layers according to the function, as the basis of the level 1 agent collected the SOS distress signal through the intelligent terminal from the elders, the database agent of layer 2 and layer 3 do cloud computing to analyze for information processing, and then the relevant data is send to the output in layer 4 management service agent, then through the sub-agent wisdom pension agent, the data continue to decompose into its sub-agents which will analyze the result and bring it to the fifth floor service agent to make corresponding decision, at the same time by the regulation of 3 agents(security agent, standard specification agent and management security agent), the whole activity can be guaranteed. Thus it can be seen that using the theory of multi-living agent is of great significance to the analysis of complex information system.

\section{Conclusion}

The research on complex information system of multi-living agent is shown in

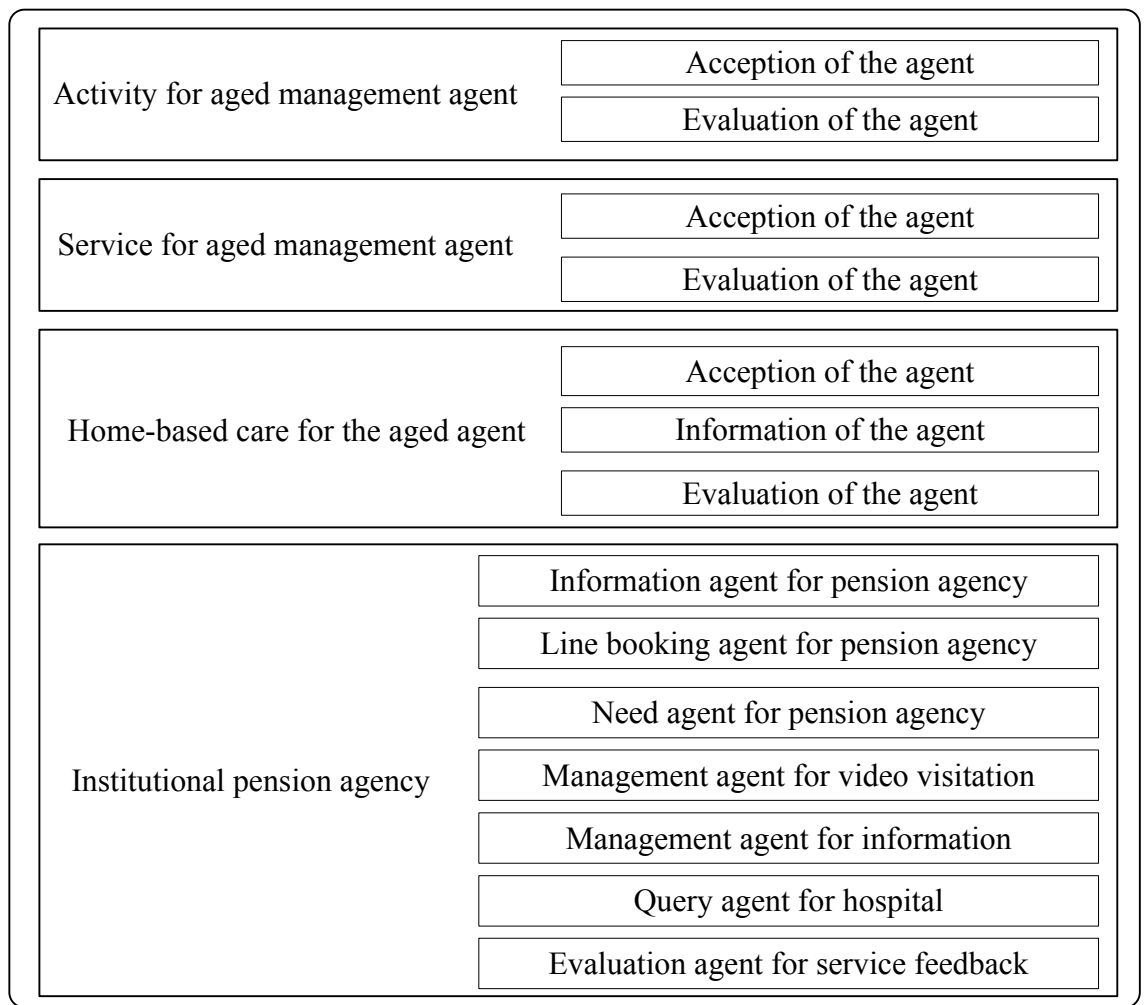

Figure 2. The frame of wisdom pension agency. 


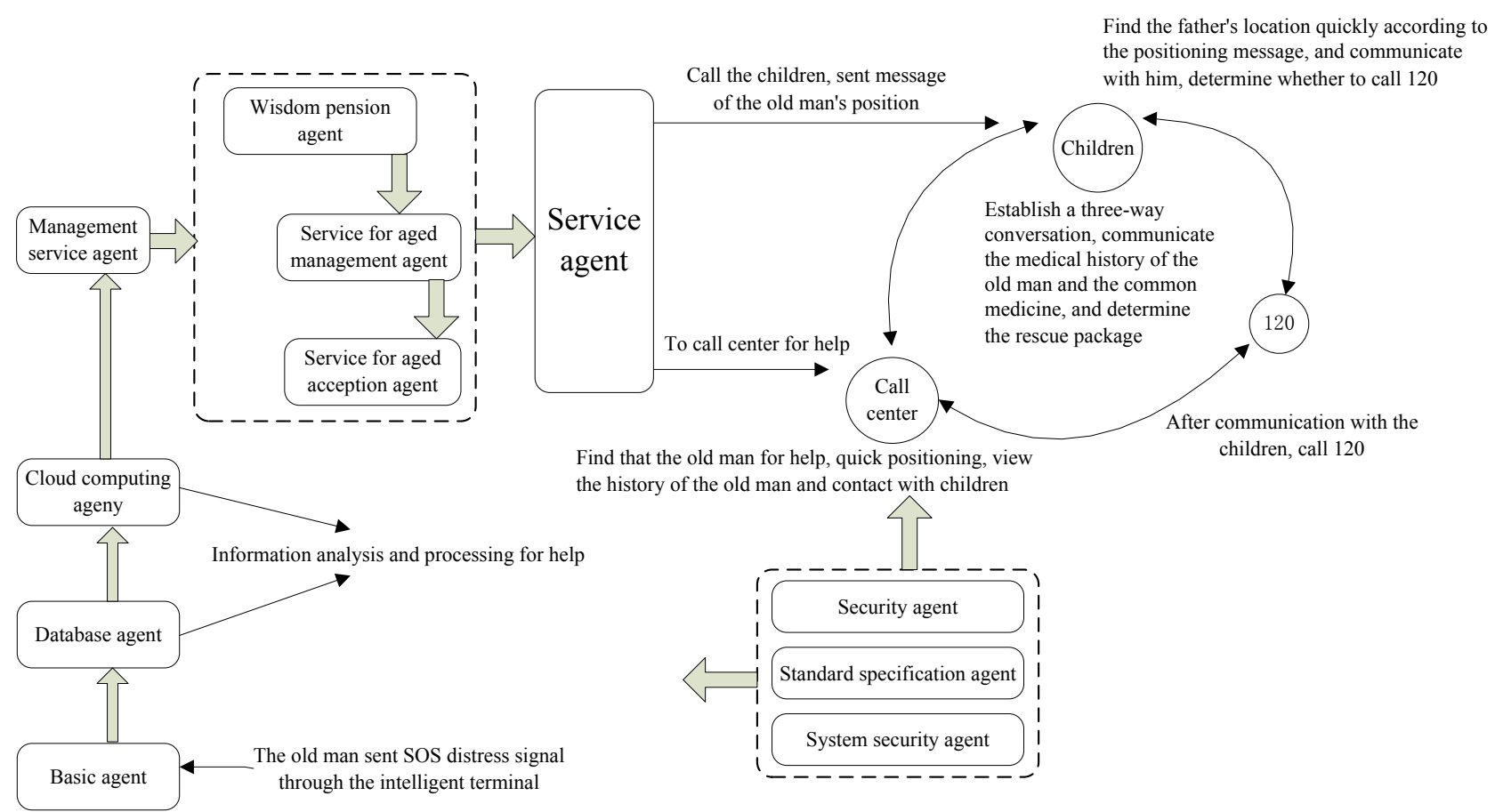

Figure 3. The application frame of wisdom pension based on the multi-living agent.

this paper. The structure of intelligent community system and the specific application of the wisdom pension are analyzed. The method of enhancing the integration from intelligent community system is also studied. Finally, a good research direction is provided to optimize intelligent community system and improve the overall performance of the intelligent community system.

\section{References}

[1] Deng, Y.S. and Xiang, T. (2013) Research on Cloud Computer Technology in Management System of Smart Community. Wireless Internet Technology, No. 1, 8-9.

[2] Zheng, C.Z., DeDao, G.U. and Gao, G.Y. (2013) Study on Countermeasure of Chinese Smart Community Service System Construction. Science and Technology Management Research, 33, 53-56.

[3] Wang, Y. and Tao, R. (2008) Research on Complex Information System Based on Multiagents. Science in China Series E, 38, 2020-2037.

[4] Dong, Z. (2011) The Study of Security Models for the Communication System in CERS Based on Multi-Living Agent Method. Multimedia Technology (ICMT), 5196-5199.

[5] Liu, S.H., Shan, T., Tao, R. and Wang, Y. (2013) Liveness Evaluation of Multi-Living Agent System. Systems Engineering and Electronics, 24, 435-444. https://doi.org/10.1109/JSEE.2013.00052

[6] Dong, Z. and Zhong, M.L. (2011) Construction of Trunking Communication System in CERS Based on Multi-Living Agent Method. Consumer Electronics, Communications and Networks (CECNet), Xianning, 6-18 April 2011, 154-157. https://doi.org/10.1109/CECNET.2011.5768811

[7] Brodie, M.L. (2010) Data Integration at Scale: From Relational Data Integration to Information Ecosystems. Advanced Information Networking and Applications 
(AINA), 2-3.

[8] Zhao, L.L., Liu, S., Li, J.S. and Wang, S.W. (2009) The Research and Design of Data Integration System for Urbanization. Education Technology and Computer Science, Wuhan, 7-8 March 2009, 831-834. https://doi.org/10.1109/ETCS.2009.447

[9] Fan, H. and Li, L. (2007) Study on Metadata Applications for Proteomics Data Integration. Bioinformatics and Biomedical Engineering, 153-156. 